\title{
PERFORMANCE ANALYSIS OF ELECTRIC VEHICLES AVAILABLE IN THE CURRENT AUTOMOTIVE MARKET
}

\author{
Florin MARIASIU ${ }^{*}$, Adela BORZAN ${ }^{1}$, Marius S. MOTOGNA ${ }^{2}$, \\ Ioan $\mathrm{SZABO}^{1}$ \\ ${ }^{1}$ Technical University of Cluj-Napoca, Cluj-Napoca, Romania \\ ${ }^{2}$ Porsche Engineering Romania, Cluj-Napoca, Romania \\ e-mail: florin.mariasiu@ auto.utcluj.ro
}

\begin{abstract}
In the current car market, electric vehicles have begun to be accepted more and more by consumers, which has led the conventional vehicles' manufacturers (and not only) to produce and sale a wider range of such vehicles. However, there is still a huge potential for development in this respect, with every car class still being available to accept new electric vehicle models. In this context, the present paper presents a research on identifying the main technical and performance characteristics of electric vehicles available in the current automotive market and establishing degrees of correlation between them. The strongest statistical correlation has been identified as finding that of the battery's energy capacity and the possible autonomy/range can be achieved for a full battery's charge.
\end{abstract}

KEYWORDS: electric vehicle, parameters, performance, autonomy, statistical correlation

\section{Introduction}

Lately, electric vehicles (EV) have gained popularity among consumers, and the motives behind them are many and diversified at the same time. The most important reason is related to their contribution to reducing greenhouse gas (GHG) emissions. In 2009 , the transport sector has emitted $25 \%$ of the total GHG generated by the energy-related economic sectors. Electric vehicles (EV), in conditions of a sufficient penetration in the automotive market and the transport sector, are expected to further reduce the level of pollutant emissions, especially in large urban agglomerations [1].

This is not the only reason for bringing back to life the old and once dead (!) concept of using electricity as a source of energy for a vehicle's propulsion group, this time this concept of the electric vehicle being produced and developed now as a viable and commercial product available to all those interested. As a vehicle, an electric propelled/powered vehicle is silent, easy to maneuver, has no fuel costs and maintenance (maintenance) associated with conventional vehicles equipped with internal combustion engines. As a means of urban transport, in the conditions of large urban agglomerations with a high degree of pollution due to transport, it is (proves to be) a very useful means of transport.

Not surprisingly, at present, the growth rate of the number of electric and hybrid vehicles in the car market is much higher than the growth of the market for conventional cars equipped with an internal combustion engine (thermal engine), and in some regions around the globe (car) electric and hybrid vehicles end up with vehicles equipped with internal combustion engines (ICE), in terms of the number of units sold annually.

With its demographic characteristics, technological development and environmental challenges, China has become the largest market for electric vehicles, with $56 \%$ of the total world sales in 2018 (compared to a market share of just $6.3 \%$ in 2013 and $35.4 \%$ in 2017 [2]). In this context, China has the largest number of electric vehicle and components manufacturers, which together sold 1200000 vehicles based on electric propulsion in 2018 (compared to 663,000 units in 2007). This huge market also attracted most car manufacturers around the world - Ford, Volkswagen, Volvo and General Motors - which have their own versions of electric vehicles on the Chinese market and are ready to introduce more / diversified models in the coming years [3]. 
From a global perspective, compared to 2017, in 2018 , the sales of electric vehicles grew by $79 \%$ in the US; Europe recorded an increase of $34 \%$, while Japan fell by $6 \%$ (!). From companies' perspective, BYD's products dominated the world market with a $13.2 \%$ share, followed by Tesla in the second place $(9.9 \%)$; the other major contributors being the Volkswagen Group, the BMW Group and Nissan. However, Tesla $\mathrm{S}$ remained the best-selling electric vehicle in the world in 2016, with 50,935 units sold, followed by Nissan Leaf EV with 49,818 units [4]. The top ten best-selling electric vehicles world-wide is shown in Figure 1.

The US market was predictably dominated by the Tesla S model in 2016 (28,821 units sold) and the Chevrolet Volt EREV model sold in 24,739 units, making it the second place. The third place was made by another model Tesla, Model X, with 18,192 SUVs also sold in 2016 [5]. Renault Zoe was Europe's most sold electric vehicle in 2016, with 21,338 units sold, followed by Nissan Leaf with 18,614 units. In the PHEV segment, Mitsubishi Outlander PHEV was the market leader in Europe in 2016, with 21,333 units sold and Volkswagen Passat GTE held its second position with 13,330 units [6]. The purpose of this article is to identify the possible existence of correlation relationships between several constructive and functional parameters characteristic of existing electric vehicles in the current automotive market, in order to provide a primary image of setting the parameters for designing and developing a new electric vehicle model.

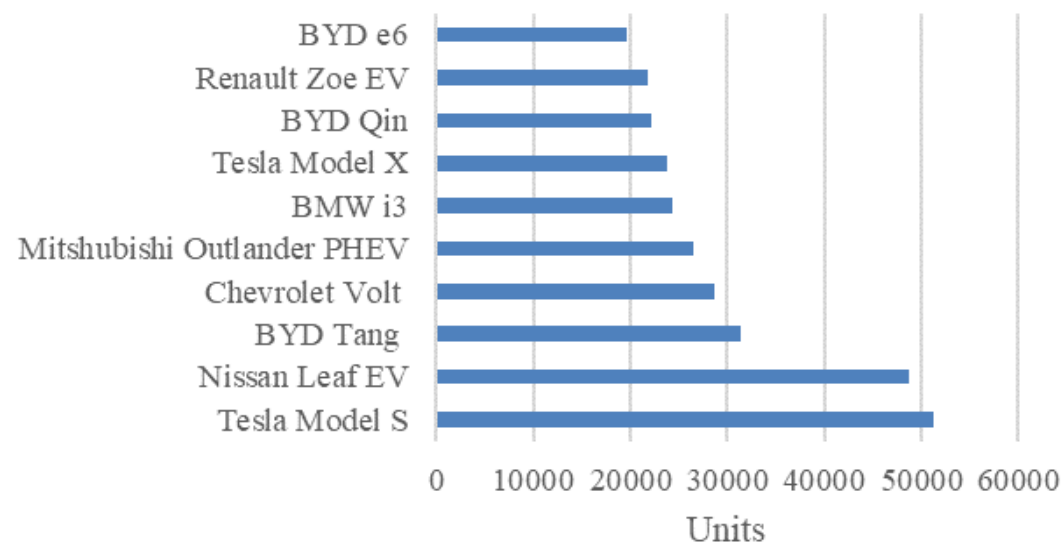

Fig. 1. Top 10 best-selling electric and hybrid vehicles worldwide in 2016 [4]

\section{Method and methodology}

The development and production of electric vehicles has been achieved through two major approaches by electric vehicle manufacturers in the current automotive market:

- Using a platform (chassis' structure and body) already existent in the manufacturer's production portfolio, the major change is the replacement of an internal combustion engine-based powertrain group with an electric propulsion group.

- Designing a new platform concept dedicated to the optimal placement in terms of weight distribution of the electric propulsion group and battery as a source of energy for it.

Table 1. Technical characteristics of EV premium class

\begin{tabular}{|c|c|c|c|c|c|}
\hline $\begin{array}{c}\text { EV type } \\
\text { Premium class }\end{array}$ & $\begin{array}{c}\text { Power } \\
{[\mathbf{k W}]}\end{array}$ & $\begin{array}{c}\text { Autonomy } \\
{[\mathbf{k m}]}\end{array}$ & $\begin{array}{c}\text { Battery energetic } \\
\text { capacity } \\
{[\mathbf{k W h}]}\end{array}$ & $\begin{array}{c}\text { Acceleration } \\
{[\mathbf{0 - 1 0 0} \mathbf{~ k m} / \mathbf{h}] \mathbf{~ s e c}}\end{array}$ & $\begin{array}{c}\text { Maximum } \\
\text { speed } \\
{[\mathbf{k m} / \mathbf{h}]}\end{array}$ \\
\hline Jaguar I-PACE electric & 300 & 386 & 90 & 4.8 & 200 \\
\hline Tesla Model 3 & 211 & 354 & 75 & 5.4 & 210 \\
\hline Tesla Model S & 285 & 416 & 75 & 5.2 & 190 \\
\hline Tesla Model X & 193 & 380 & 75 & 6.0 & 210 \\
\hline Tesla Roadster & 514 & 1000 & 200 & 1.9 & 400 \\
\hline Porsche Taycan & 440 & 500 & 90 & 3.5 & 250 \\
\hline Audi E-Tron electric & 300 & 328 & 95 & 5.5 & 200 \\
\hline
\end{tabular}


In both above-mentioned approaches, it has been attempted to reduce the overall weight of the vehicle, because weight is an important parameter in achieving a maximum distance in $\mathrm{km}$ that can be covered with a single (full) charge of the battery (EV's autonomy).

For the global performance and technical characteristic analysis of electric vehicles present in the current car market, the main models available for sale in Europe (23), from a number of 14 manufacturers and divided into 3 characteristic classes were considered.

The main parameters considered for the proposed analysis were the vehicle type, the power of the electric engine, the energetic capacity of the battery, the acceleration and the maximum speed. These data are presented in Tables 1-3.

Table 2. Technical characteristics of EV compact class

\begin{tabular}{|c|c|c|c|c|c|}
\hline $\begin{array}{c}\text { EV type } \\
\text { Compact class }\end{array}$ & $\begin{array}{c}\text { Power } \\
{[\mathbf{k W}]}\end{array}$ & $\begin{array}{c}\text { Autonomy } \\
{[\mathbf{k m}]}\end{array}$ & $\begin{array}{c}\text { Battery energetic } \\
\text { capacity } \\
{[\mathbf{k W h}]}\end{array}$ & $\begin{array}{c}\text { Acceleration } \\
{[\mathbf{0 - 1 0 0} \mathbf{~ k m} / \mathbf{h}]} \\
\mathbf{s e c}\end{array}$ & $\begin{array}{c}\text { Maximum } \\
\mathbf{s p e e d} \\
{[\mathbf{k m} / \mathbf{h}]}\end{array}$ \\
\hline Honda Clarity electric & 120 & 143 & 25.5 & 7.6 & 140 \\
\hline Ford Focus electric & 107 & 185 & 35 & 9.9 & 135 \\
\hline Hyundai IONIQ & 88 & 200 & 28 & 9 & 165 \\
\hline Hyundai KONA I e & 99 & 300 & 39 & 9 & 160 \\
\hline Hyundai KONA II e & 150 & 415 & 64 & 7 & 180 \\
\hline Nissan LEAF & 110 & 242 & 40 & 8 & 140 \\
\hline Nissan LEAF e-Plus & 160 & 360 & 60 & 6.3 & 200 \\
\hline Chevrolet BOLT & 149 & 383 & 60 & 6.5 & 150 \\
\hline Volkswagen e-Golf & 98 & 190 & 35.8 & 9.6 & 149 \\
\hline KIA NIRO all-electric & 149 & 384 & 64 & 7.8 & 167 \\
\hline KIA SOUL all-electric & 89 & 178 & 30 & 11 & 144 \\
\hline
\end{tabular}

Table 3. Technical characteristics of EV small class

\begin{tabular}{|c|c|c|c|c|c|}
\hline $\begin{array}{c}\text { EV type } \\
\text { Small class }\end{array}$ & $\begin{array}{c}\text { Power } \\
{[\mathbf{k W}]}\end{array}$ & $\begin{array}{c}\text { Autonomy } \\
{[\mathbf{k m}]}\end{array}$ & $\begin{array}{c}\text { Battery energetic } \\
\text { capacity } \\
{[\mathbf{k W h}]}\end{array}$ & $\begin{array}{c}\text { Acceleration } \\
{[\mathbf{0 - 1 0 0} \mathbf{k m} / \mathbf{h}]} \\
\mathbf{s e c}\end{array}$ & $\begin{array}{c}\text { Maximum } \\
\text { speed } \\
{[\mathbf{k m} / \mathbf{h}]}\end{array}$ \\
\hline BMW i3 & 125 & 180 & 33.2 & 7.3 & 150 \\
\hline Mini Cooper e & 125 & 320 & 42 & 6.7 & 160 \\
\hline Fiat 500e & 83 & 135 & 24 & 8.4 & 141 \\
\hline Mitshubishi i-MiEV & 48 & 160 & 35 & 13 & 128 \\
\hline Smart FORTWO e & 30 & 161 & 17.6 & 11.5 & 130 \\
\hline
\end{tabular}

The conjugate parameters for the analysis were: autonomy versus battery capacity, (engine) power vs. battery capacity, acceleration vs. maximum speed and energy efficiency of the vehicle reported over the distance (in $\mathrm{km}$ ) possible to travel with a consumption of $1 \mathrm{~kW}$, in an attempt to establish whether there is a dependency relationship between them. Parameter dependence may provide a primary picture of the initial design process of a new electric vehicle.

\section{Results and discussions}

The results obtained by the comparative analysis of two by two parameters characteristic of the electric vehicles considered in this study are presented in Figures 2 - 5 . 


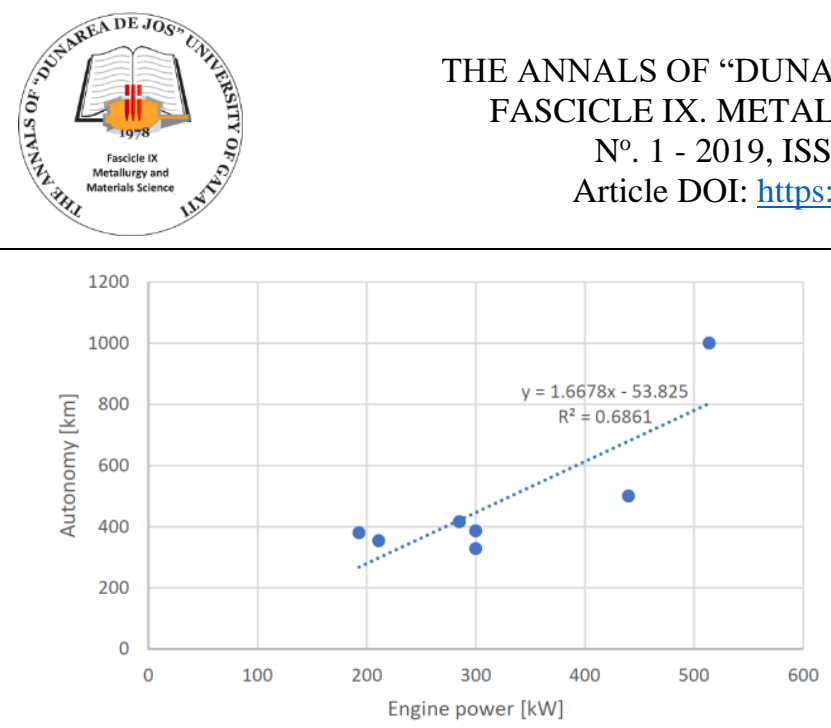

A

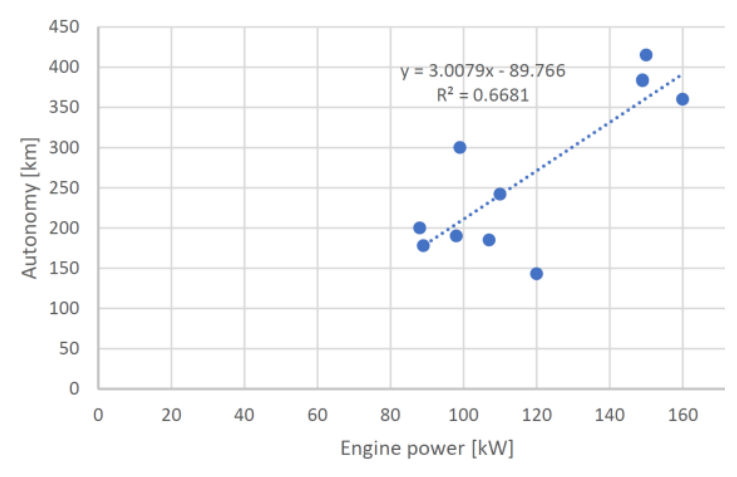

b

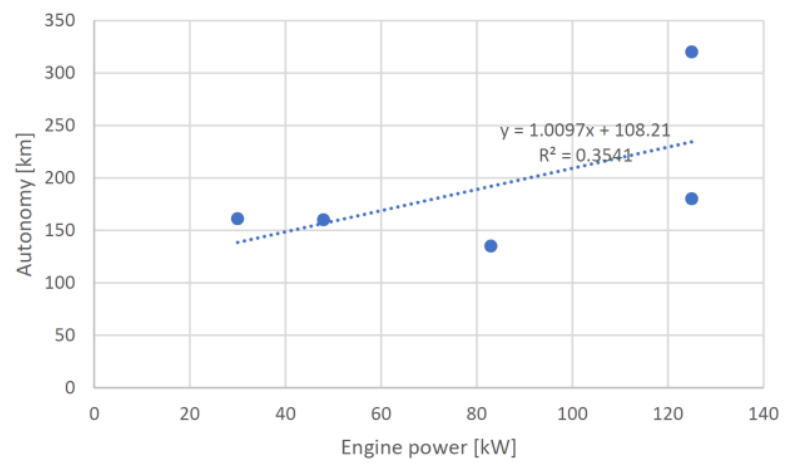

$\mathrm{C}$

Fig. 2. Correlation of technical characteristics and performance for autonomy vs. engine power (apremium class; $b$-compact class; $c$-small class)

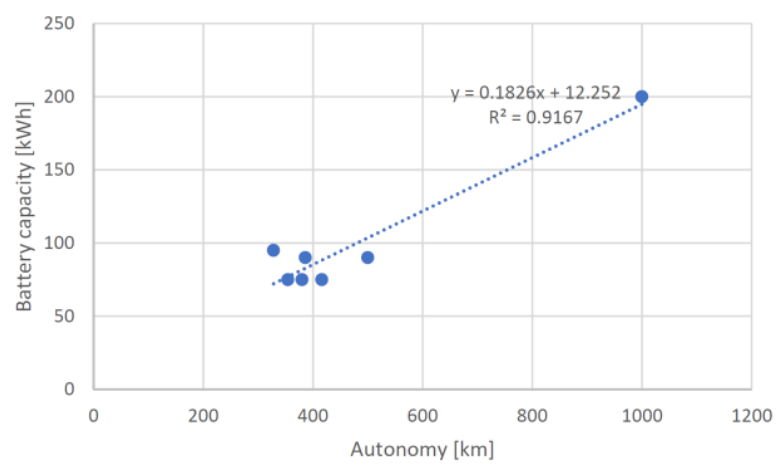

A

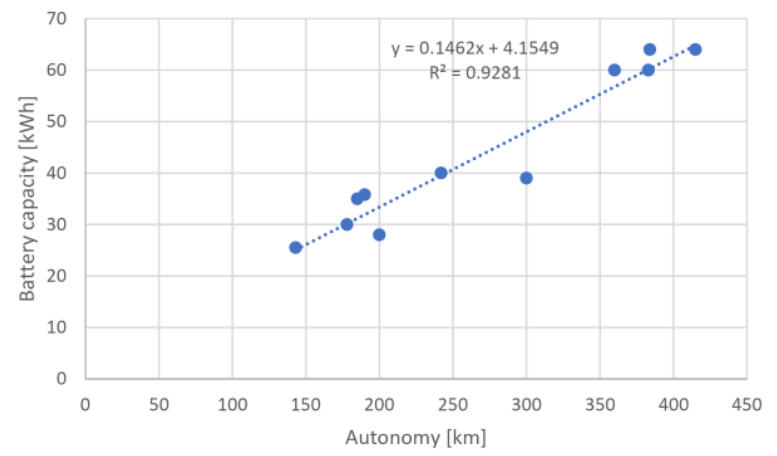

b

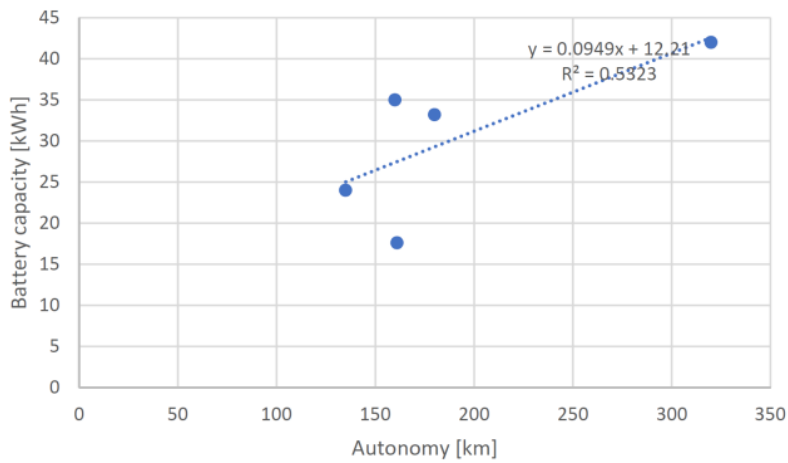

$\mathrm{C}$

Fig. 3. Correlation of technical characteristics and performance for battery capacity vs. autonomy ( $a$ premium class; $b$-compact class; $c$-small class) 


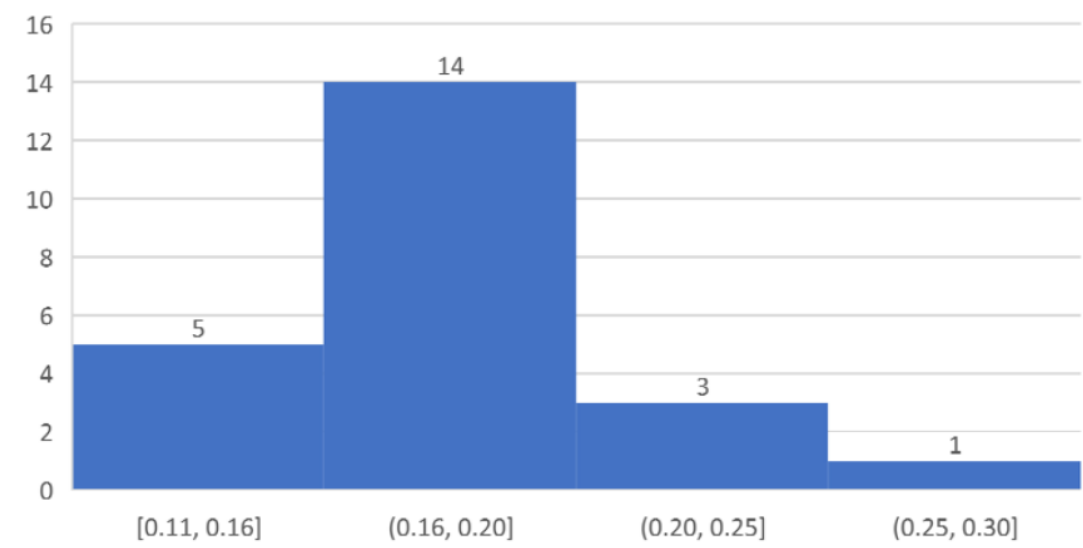

Fig. 4. Histogram repartition of all classes EV's energetic consumption

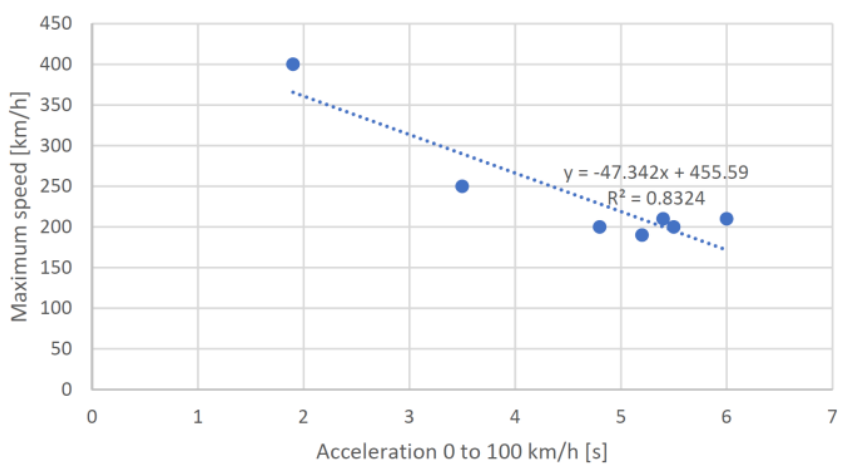

A

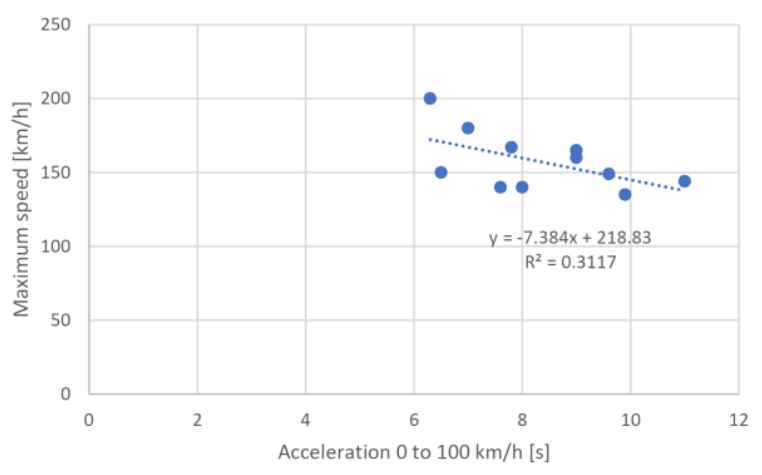

$\mathrm{b}$

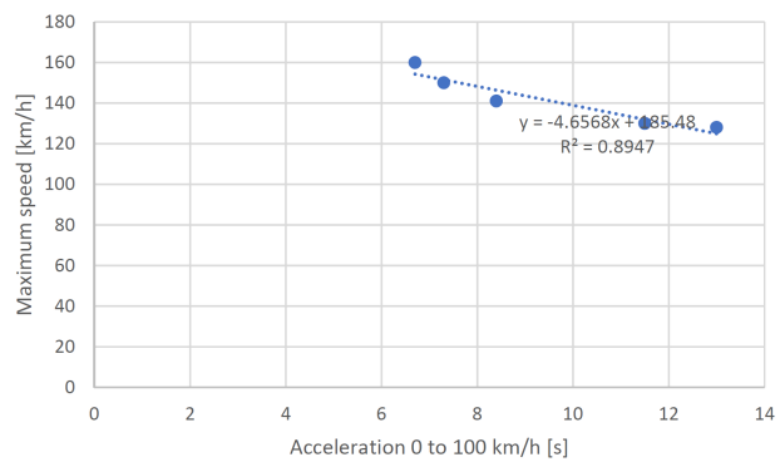

Fig. 5. Correlation of technical characteristics and performance for maximum speed vs. acceleration 0 to $100 \mathrm{~km} / \mathrm{s}$ (a-premium class; b-compact class; c-small class)

The linear correlation was considered in the present study in order to find a straight and direct link between technical characteristics and EVs' performance.

From the point of view of the correlation between autonomy versus engine power, we notice that the best $\mathrm{R}^{2}$ value is for premium class (0.686), and at a close value is that of the compact class (0.668) (Figure 2). The weakest correlation is encountered in the low class, the $\mathrm{R}^{2}$ coefficient having the value of 0.354 . This can be interpreted by placing greater emphasis on the design of the electric propulsion group for premium and compact classes (plus the advantage of being more powerful through the space available through body and chassis construction).

Similarly, if we see that for the premium and compact class the correlation between the battery capacity vs autonomy for the considered EVs, has 
high values $\left(\mathrm{R}^{2}=0.916\right.$ for the premium class and $\mathrm{R}^{2}$ $=0.928$ for the compact class) (Figure 3 ).

These car market segments represent, in fact, the majority of the vehicles sold, and therefore the manufacturers did their best to produce models to meet the main requirement of the customers, which is to have autonomy closest to that of conventional vehicles equipped with an internal combustion engine using fossil fuels.

Low values of correlation factor $\mathrm{R}^{2}=0.552$, in the case of the small class, can be explained by the fact that for these vehicles the main design factor is that of minimizing geometric dimensions. This results in a limitation of the size of the battery that can be placed inside the vehicle's body/chassis and directly the limitation of the battery's energy capacity.

Furthermore, in the automotive market, the small-segment vehicle segment is a low-end segment as a share of the total sales of vehicles overall class. Small-class electric vehicles have been designed and developed in order to be a "second family car" and "a green alternative" to customers for urban use.

From the point of view of comparing the dynamic performance of EVs (maximum speed vs. acceleration), the situation is different from the above. If the premium class and the small class correlations are high $\left(\mathrm{R}^{2}=0.832\right.$ for the premium class and $\mathrm{R}^{2}=0.894$ for the small class), the weakest correlation is for the compact class $\left(\mathrm{R}^{2}=0.311\right)$ (Figure 5). If in the case of a small class, the high correlation factor results from the overall reduced weight of the vehicle, and for the premium class to meet customer requirements regarding dynamic performances, the compact class EV is designed to be used more for urban traffic where average speeds in large urban clusters are very low and there are numerous stops.

\section{Conclusions}

With the increasing demand in the current car market for different electric vehicles, manufacturers are trying to offer as many models as possible to meet the needs and expectations of customers (clients).

The autonomy of an electric vehicle is directly related to the energetic capacity of the battery, so it can be stated that autonomy is the main factor considered in primary fazes of EV's design and development. The best correlations between the technical parameters and the characteristics of the EVs considered are obtained for the premium class, all of which are required by customers in this market segment.

The compact EV class delivers the autonomy demanded by customers but is primarily designed for urban use, while the small class of electric vehicles is an environmentally-friendly alternative to the use of transport means for passengers.

From the point of view of the energy efficiency of the electric vehicles taken into consideration, the energy consumption of most electric vehicles (14 types) is between $0.16-0.20 \mathrm{~km} / \mathrm{kW}$ (Figure 4).

The results of this study can also use initial data (primary) for the design and development of a new electric car model.

\section{Acknowledgment}

This research was funded by the Program "POCA1-A1.2.3-G-2-15 Parteneriate pentru transfer de cunoştinţe, nr. contract de finanţare: 11/01.09.2016, titlul proiectului: Tehnologii pentru vehicule electrice urbane inteligente URBIVEL, ID: P_40_333, MySMIS: 105565".

\section{References}

[1]. Yong J. Y., Ramachandaramurthy V. K., Tan K. M., Mithulananthan N., A review on the state-of-the-art technologies of electric vehicle, its impacts and prospects, Renew. Sustain. Energy Rev., 49, p. 365-385, 2015.

[2]. ***, Worldwide EV Sales Are on The Move, online: http://evercharge.net/blog/infographicworldwide-ev-sales-are-onthe-move/ (accessed on 12 May 2019).

[3]. ***, China's Quota Threat Charges Up Electric Car Market, online: http://www.thedailystar.net/business/chinas-quota-threatcharges-electric-car-market-1396066/ (accessed on 12 May 2019).

[4]. ***, EV-Volumes-The Electric Vehicle World Sales Database, online: http://www.ev-volumes.com/country/total-world-plug-invehicle-volumes/ (accessed on 8 May 2019).

[5]. ***, EV-Volumes-The Electric Vehicle World Sales Database, online: http://www.ev-volumes.com/country/usa/ (accessed on 8 May 2019).

[6]. ***, European Alternative Fuels Observatory-M1 statistics, Available online: http://www.eafo.eu/vehicle-statistics/m1 (accessed on 8 May 2019). 